\title{
Numa cama, numa greve, numa festa, numa revolução: notas sobre materialidades de uma experiência estética
}

Érico de Oliveira de Araújo Lima

Resumo: Este artigo aborda o filme A Idade da Terra (Glauber Rocha, 1980), segundo uma abordagem teórico-metodológica que destaca as materialidades da imagem e do som. Existem aqui dois gestos: um de caráter analítico, que tenta efetuar um contato material com a obra destacada; e um segundo gesto, de tonalidade conceitual, que consiste em situar a discussão sobre as materialidades dos objetos da comunicação. No caminho por essa pesquisa de conceitos, encontramos uma vinculação fundamental entre a dimensão temporal das formas e a materialidade da experiência estética.

Palavras-chave: materialidades; experiência; montagem; Glauber Rocha.

Abstract: In bed, in strike, in feast, in revolution: notes on the materiality of an aesthetic experience

- This paper discusses the film A idade da terra (Glauber Rocha, 1980), according to a theoretical-methodological approach that highlights the materiality of picture and sound. There are two gestures here: an analytical gesture, which tries to establish a material contact to the film in question; and the other one, of conceptual tone, which consists in situating the debate on the materiality of communication objects. Through the path of this research for concepts, we have found a fundamental bind between the temporal dimension of forms and the materiality of the aesthetic experience.

Keywords: materiality; experience; montage; Glauber Rocha.

1817. O físico escocês Dawid Brewster inventa na Inglaterra o caleidoscópio. Esse aparelho óptico, que é também um brinquedo, é formado por pequenos e variados fragmentos de vidro que refletem a luz exterior e possibilitam, a cada olhar, infindáveis combinações e arranjos. Um jogo de espelhos. Novas percepções se formam tanto a partir 
do dispositivo visual contido no aparelho quanto por conta do movimento de quem o toma, de como se joga com ele.

Dentro de uma matriz de pensamento que considera os objetos da comunicação como produtores de efeitos de presença, gostaríamos de trazer a discussão sobre as materialidades em uma proposta de análise fílmica. Busca-se aqui fazer um movimento que cruza comunicação e experiência estética e aposta em uma abordagem teórica e metodológica atenta à realidade física da escritura fílmica. Trata-se de uma operação que acompanha de perto imagem e som em suas potências de ocupar o mundo, instalando-se, como presença, nos corpos e na vida.

Essa busca é exigida pelo próprio confronto com o filme aqui em questão, $A$ Idade da Terra (1980), de Glauber Rocha, que pode ampliar olhares e sensibilidades ao demandar, não só uma interpretação, mas, sobretudo - pelo menos, este será o foco aqui - uma postura teórico-metodológica que faz tensão com abordagens hermenêuticas e metafísicas. Assim, talvez, seja possível se colocar, efetivamente, dentro de um verdadeiro fluxo audiovisual. Não se trata de estabelecer aqui uma dicotomia com o gesto da interpretação, mas de fazer a ênfase recair mais em uma perspectiva que toma a própria imagem como um corpo potente em afetar outros corpos, a saber, os dos próprios espectadores. Em uma tripla relação corpórea - os corpos dos atores, internos à cena, o corpo fílmico e o corpo do espectador - residiria uma aposta para pensar o lugar da experiência que emerge como matéria fílmica. Seria uma tentativa de permitir-se arrastar pelas desorientações sensíveis promovidas por Glauber e de acompanhar os movimentos de abertura ao mundo desencadeados por ele. "A Idade da Terra é um filme que o espectador deverá assistir como se estivesse numa cama, numa festa, numa greve ou numa revolução. É um novo cinema, antiliterário e metateatral, que será gozado, e não visto e ouvido" (ROCHA, 1979 apud BENTES, 1997, p.67).

Ao tomarmos essa provocação glauberiana como motivo melódico para nossa análise, apostamos que existe aí uma radical defesa de um transbordamento do cinema com o mundo, numa associação fundamental entre experiência fílmica e experiência vivida. Mais largamente, isso implica que a experiência estética deve ser mesmo pensada no contágio entre os objetos da arte e as experiências de todos os dias. Ou dizendo de outro modo, a vida e a arte se encontram aí em uma íntima relação de coengedramento, de modo que a matéria da vida se faz obra de arte, e a obra de arte se engaja com a vida - não apenas discursivamente, mas, sobretudo, materialmente, eis o que tentaremos articular aqui.

Se pensamos nas imagens de Glauber em A Idade da Terra, as formas expressivas em jogo nelas podem ser pensadas menos em termos das significações que desencadeiam - 
ainda que isso não precise ser desconsiderado em outras análises - e mais pelas forças que captam, pela maneira como ocupam os corpos e se produzem, elas mesmas, como corpos. É também na própria expressão textual de Glauber que esse novo regime de sensibilidade tem elaboração, na medida em que as teorizações sobre a estética do sonho vão promover inflexões em modelos que ainda partiam de esquemas, de expectativas de causalidades e de construções teleológicas. A partir desse momento das pesquisas do realizador, o irracional vai se transformar em uma aposta estética e política para atuar no mundo, como elemento que coloca em crise aquilo que ele chamava de uma racionalidade burguesa. Em seu texto Eztetyka do Sonho (1971), que nos parece central para compreender as transformações pelas quais sua cinematografia passou ao longo dos anos 1970 até o desembocar do filme final, torna-se bastante urgente a busca pela irrupção de uma anti-razão como forma de articular arte e revolução, para além de uma explicação racional e dedutiva sobre as condições do País.

Ao longo dos anos 1970, Glauber explora ainda uma ideia de montagem nuclear, mencionada pela primeira vez quando realiza Di Cavalcanti (1977) e radicalizada nas desorganizações dos blocos fílmicos em A Idade da Terra. Pensava também em um Kynorama, cinema espacial e integral, universo cinematográfico total (ROCHA, 2004, p. 383). A todo o momento, era um desejo de habitar o mundo e de ter lugar, de ampliar os possíveis do cinema, que já não se bastava em formas fixas e legitimadas, em dispositivos pré-moldados, seja o arquitetônico, seja o que estipulava a organização e ordenação das imagens na elaboração de significados. Era preciso sair da tela. Os caminhos experimentados por Glauber aí já não significam discursivamente, mas são protocolos de experiência, recorrendo a termo utilizado por Deleuze e Guattari (2003).

Para situarmos a maturação do projeto de $A$ Idade da Terra, vale remontar ao gesto de impulso em Di Cavalcanti. Nesse curta-metragem, o realizador chega a definir verbalmente a ideia de uma montagem nuclear (nunca sistematizada em termos teóricos mais estritos, mesmo em seus textos) como excesso e acúmulo: "a quantidade está na qualidade" podemos ouvir na voz off. Essa perspectiva, lançada como proposta no curta-metragem, é levada adiante como explosão ainda mais intensa, na subversão de tempos e de espaços de $A$ Idade da Terra, com a ênfase marcada no fragmentar, na disjunção e na simultaneidade. Era projeto de Glauber, inclusive, exibir esse filme em uma ordenação aleatória dos 16 rolos. É um filme de acúmulos e intensidades, que chegou a ter um primeiro corte com mais de quatro horas de duração, sendo reduzido depois para as duas horas e meia e na conformação de uma montagem que já não seria projetada aleatoriamente nas salas de cinema, por limitações logísticas com a Embrafilme na época do lançamento. Ainda assim, temos aí uma montagem que convida o espectador a entrar no filme a partir de vários pontos, fazer vários percursos diferentes, alterar o próprio corpo no contagiar-se pelas imagens. Poderíamos dizer que se trata aí de um filme que acontece com o espectador, que demanda o corpo dele. Arriscamos mesmo falar de um cinema de instalação contido 
na própria escritura das imagens, transbordando a tela, quebrando a moldura, saltando para ocupar a cidade, a polis. Esse filme de Glauber parece convocar a uma outra maneira de experimentação, e talvez a proposta de um Kynorama fosse efetivamente uma saída em termos de uma matéria espaço-temporal.

Um Kynorama seria o cinema integral. O próprio filme é a própria sala de projeção. Você entra na sala, ali dentro é um filme. Tudo é um filme, inclusive o espectador integrado. É o estúdio, é projeção, é tudo. O mesmo que um universo cinematográfico total (ROCHA, 2004, p. 383).

Seria importante então fazer um breve percurso para precisar alguns conceitos e ainda tomar cuidado com algumas dicotomias. Falar em materialidade não implica uma oposição ao que estaria fora da matéria. Esse seria um primeiro cuidado tanto do ponto de vista teórico quanto no que reverbera para o gesto analítico. Pois não se trata de pensar em esquemas cartesianos e separar o corpo da mente ou opor, conceitualmente, um mundo material de outro imaterial. Flusser (2007) promove toda uma genealogia das palavras para nos indicar que já não há mais sentido em separar dimensões tão imbricadas quanto forma e matéria. Na percepção dos fenômenos, o formal e o material estão entrecruzados, e é particularmente equívoca a noção de cultura imaterial. As formas não são algo a ser descoberto ou desvelado para além da matéria ou sob a materialidade do mundo.

Não é o caso de se perguntar se as imagens são superfícies de matérias ou conteúdos de campos eletromagnéticos. Convém saber em que medida essas imagens correspondem ao modo de pensar e de ver material e formal. Seja qual for o significado da palavra "material", só não pode exprimir o oposto de "imaterialidade". Pois a "imaterialidade", ou, no sentido estrito, a forma, é precisamente aquilo que faz o material aparecer. A aparência do material é a forma (FLUSSER, 2007, p. 32).

Nesse sentido, as relações binárias podem ser esmaecidas, de modo que podemos nos situar em zonas de vizinhança, compondo com o pensamento de Deleuze e Guattari (1995). Estamos em outra ordem de pensamento que já não cria lugares estabelecidos e fixos, mas nos retira das identidades marcadas para cada dimensão da experiência. A questão não se coloca como busca por verdades além das superfícies, porque é todo um novo regime de sensibilidade e de pensamento que se configura. Não tem mais sentido o problema de uma busca por profundidades ocultas no mundo - elogio da superficialidade é a proposta de Flusser para a nova sensibilidade que está em jogo com as imagens técnicas. Diríamos, então, que é já na superfície que se engendram dentro e fora, mundo diegético, realidade física do filme e uma comunidade de espectadores. Desvelar seria 
ir além dos véus, ultrapassar a superfície, buscar essências - e isso já não é necessário: “Os nossos véus não encobrem nada, mas são a nossa resposta ao nada. [...] Não rasgá-los, mas tecê-los" (FLUSSER, 2008, p.44). É o estar-no-mundo que se altera, os paradigmas de olhar, de ouvir e de sentir, em meio a véus que se adensam e se tecem ininterruptamente.

Pensar as imagens em aspecto da materialidade implica uma maneira de aproximarse delas, na dimensão dos ritmos, vibrações, constituição de formas e sensibilidades, considerando esses aspectos como indissociáveis do laço que estabelecem com a tessitura da cena e com a experimentação afetiva das matérias. Aqui vale enfatizar que a imagem do pensamento da imanência parece-nos mais rica que a da transcendência: isso implica dizer que o filme não sobrevoa o mundo sensível, para produzir uma mimese exterior a ele, ou que a cena circunscrita se afastaria das figuras inscritas na superfície. Se trabalharmos com um plano de imanência, podemos destacar a matéria como constitutiva e constituinte de mundos múltiplos em circulação num mesmo plano e horizonte de possibilidades, sem a verticalidade da matriz de pensamento transcendental. A matéria fílmica se insere, como fluxo, no fluxo da vida, atravessando as matérias do mundo e se fazendo na vizinhança com elas.

Tentamos, então, pensar o cinema de Glauber afetando os corpos, a própria imagem como um corpo que nos toma e que ocupa o mundo. O realizador já tinha um desejo bastante marcado de fazer as imagens saltarem da tela, numa dimensão que parece bastante material e corpórea. Numa cama, numa festa, numa greve ou numa revolução, formas novas para a experiência de uma obra cinematográfica podem ser instauradas - e então, em alguma medida, toda a importância de ter um corpo estaria em jogo aí, de implicar o corpo inteiro na experimentação desses corpos fílmicos. As culturas de presença (GUMBRECHT, 2010), em fissura com as culturas de sentido, encaminham olhares distanciados da tentativa de compreender os fenômenos em relação com sentidos mais elevados que sua presença material. Valeria, assim, tentar uma abordagem que não considere, exclusivamente, as superfícies materiais num para além das forças que suscitam. É uma maneira de perceber as visualidades como seres que participam do mundo, que o habitam. A imagem tem, então, uma maneira de trabalhar e constitui toda uma pragmática material.

Essa abordagem conceitual vai centrar-se nas coisalidades e em como estas dimensões afetam os corpos. No mundo da cultura da presença, "os seres humanos querem relacionar-se com a cosmologia envolvente por meio da inscrição de si mesmos, ou seja, de seus próprios corpos, nos ritmos dessa cosmologia" (GUMBRECHT, 2010, p.109). Trata-se de um corpo que se inscreve no mundo e pode relacionar-se às temporalidades, aos espaços, às formas. Esse corpo não está desvinculado, mas é parte implicada na experiência estética, nos caminhos pelo mundo e na relação com as imagens e sonoridades. Nossos corpos são lugar da experiência estética. 
Se pensamos em imagem, é preciso então considerar uma série de elementos fundamentais para a experiência de fruição: as texturas, os jogos de luz e sombra, as modulações de cor, os elementos constituintes da película, que chegam mesmo a ser expostos quando Brahms (Maurício da Valle), o Cristo Militar (Tarcísio Meira) e Danuza Leão conversam em frente a uma placa da Coca-Cola e a imagem adquire um tom mais escuro e cheio de grãos, com uma luz que entra pela lateral, como num evidência sensível do material fílmico. Mas a recorrente ênfase aqui à noção do que é próprio à imagem não quer dizer um retorno ao paradigma moderno, de uma pura forma e de uma abstração do entorno da imagem, nas forças que ela estabelece com o mundo. Não se trata de um formalismo, é importante destacar. Na verdade, apostar na materialidade e na superfície é pensar justamente a imagem em sua exposição ao fora, nos trânsitos que ela estabelece com a experiência cotidiana.

É na presença sensual da superfície que estão em conexão heterogeneidades. As descontinuidades que sentimos de uma imagem a outra nas séries desencadeadas pela matéria fílmica são operações sensíveis no próprio descompasso da plasticidade, que não mimetiza o mundo, mas investe novas questões para a experiência, traça um plano de composição e novos problemas de ordem estética e política. Diante de uma imagem, nunca é apenas um estar diante que se coloca em questão, nem apenas uma imagem que se apresenta ao ver, mas tem-se um conjunto de forças agenciadas e agenciadoras de perceptos e afetos, uma região de prováveis e de possíveis que vão complexificar a vida e relançar categorias.

Na celebração do carnaval no Rio de Janeiro, em um dos blocos sensíveis que compõem a estrutura de $A$ Idade da Terra, já se instala um toque do samba, na batida dos tamborins e no canto entoado. Um primeiro plano dá a dimensão do conjunto, ele é geral e aberto, e o movimento no quadro se faz ver pelos modos de cada um dançar na multidão. Há uma distância da câmera em relação aos sujeitos filmados, eles são incialmente vários pontos espalhados pelo espaço, em agitação e dança. Os tons de azul e branco, vestidos por todos da escola de samba, criam uma primeira impressão de unidade, já que se trata de um corpo coletivo que se performa em determinada cadência organizada previamente, ensaiada várias vezes, para o desfile no sambódromo. Mas esse conjunto vai ser desmontado aos poucos, e o que se apresentava como um todo passa a ser isolado em partes, que uma vez dispersas, já não poderão mais ser reunidas.

A sucessão de cortes rápidos na sequência percorre os retalhos que foram feitos pela câmera. E esses fragmentos se seguem um ao outro, sem que estejam ligados segundo um princípio de identidade ou de narração, mas pela curva que podem criar na sensação, pela maneira como um atrai o outro e pode criar um campo de ressonância. O filme coloca seus personagens em meio ao acontecimento: podem ser reconhecidos Brahms, Aurora Madalena e o Cristo Militar, também integrados à festa. Um plano mais longo se dedica, especialmente, ao rosto desse Cristo que surge nessa sequência, enquanto percorre 
o desfile, entre os integrantes da bateria, destacando-se em meio à multidão, tanto pela roupa quanto pelo outro ritmo que parece ter no corpo. Ele olha o entorno, acena, sorri. É com muita sutileza que começa a reverberar no rosto o batuque, com movimentos leves de cabeça e, aos poucos, também das mãos. A câmera chega mais perto, filma apenas a boca, desfoca a imagem nessa aproximação, e depois se distancia. Ora o personagem se perde em meio a todos, ora é reencontrado, no percurso simultâneo de quem filma e de quem é filmado.

O plano é cortado no desenrolar mesmo dos gestos do ator. Seguem-se mais imagens em meio às pessoas, no recorte de vários instantes dispersos do desfile, carros alegóricos, setores diferentes do espaço. É a composição de um mural, mas um mural repleto de figuras que não necessariamente se encaixam. O cortejo das pessoas parece ir e vir em diferentes sentidos, a montagem desfaz as coordenadas do espaço, ela cria uma outra possibilidade de percorrê-lo visualmente. De repente, surge um momento emblemático dessa rítmica singular criada pela associação livre entre os fragmentos. Uma música sinfônica passa a intervir e a se misturar ao som direto do samba, o tempo de cada fragmento é reduzido, até que tudo se transforma em flashes de sucessão acelerada, imagens de todos dançando, numa montagem que parece um piscar frenético de olhos. Aurora Madalena é a personagem do filme que agora está focada em meio aos muitos homens e mulheres que dançam as cores do carnaval, e o método de embaralhar a presença do corpo dela se dá por uma intensificação do batimento fílmico, quando o rodopio dos corpos no âmbito da cena vira rodopio de imagens. É uma vertigem, é uma deriva completa dos sentidos. O plano é implodido, a transição é salto. A imagem que se segue à outra não dá continuidade ao movimento iniciado antes nem tem função de sentido, como quando um fragmento pode ter o papel narrativo de tornar um detalhe mais visível no conjunto. $\mathrm{O}$ antes e o depois se perdem pelo meio, uma imagem pode ser repetida ou interrompida de súbito, ela pode ser um plano mais próximo ou mais distante, um quadro mais aberto ou mais fechado, mas o que a reunião de tudo em acelerada sucessão faz ver é a própria experiência de acúmulo, o próprio intervalo e o gesto da montagem mesma.

Tudo gira. São várias imagens num curto intervalo de tempo. A simultaneidade aqui não se dá por paralelismo de ações, mas por imagens que não se sustentam para o olhar. Não há também jogo de oposições nem a expressão de contradições. As partes são corpos libertos de uma linha significante, elas aparecem como intensidades que cortam um contínuo e excedem níveis. Existem, nesse espaço do sambódromo, várias ações simultâneas, diferentes corpos em movimento, cada um com seus gestos, com seu ritmo, construindo a dança no carnaval. No momento em que todos aparecem em sucessão, com a velocidade de um foguete contaminando as velocidades das imagens, eles criam um bloco de forças em que tudo se arremessa, tudo vive ao mesmo tempo, tudo dança. Cria-se uma espessura de imagem, mais do que uma sucessão ou uma linha sintagmática. Cada gesto é visto em um instante, um braço que se levanta, um rosto que se dirige 
à câmera, um corpo que se agita. E todos esses pequenos gestos, que não se prolongam nem se desdobram em uma ação final, são montados no compasso de festa. Cada um dos relances e dos lampejos que surgem não vira uma soma, todos criam a experiência de turbilhão. Não existe mais totalidade possível nem conclusão final. As formas montadas em A Idade da Terra crescem pelo meio.

A sequência do Carnaval é permeada pela dimensão explosiva da montagem nuclear, que concentra as energias em curtos intervalos de tempo e faz a passagem das imagens se acelerar em uma experiência de irrupção do filme para o mundo. É a obra mesma que se transforma num foguete que, ao se propagar, gera todo um efeito explosivo no seu entorno. As partes espalhadas se sustentam como partes, ressoando umas nas outras de formas variadas, podendo constituir sempre mais configurações e arranjos. E quando se reúnem, desencadeiam muito mais vibrações do que uma conclusão sintética que estaria no Uno ou no Todo. A arbitrariedade e a independência das escolhas dos pedaços, como na montagem de atrações em Eisenstein, se modulam em Glauber como radicalização de um pensamento: o arbitrário do encaixe pode ser tanto mais potente na medida em que uma conclusão de síntese também for desorganizada. A apreensão do filme se investe de uma virtualidade infinita de relações que podem ser desencadeadas no contato com o mundo e com o espectador.

Núcleos autônomos, dissonantes, sem ordenação vertical. Fluxo intensivo que circula e se bifurca, sofre interrupções abruptas e se ramifica. As tensões são entre as imagens, entre imagens e sons, entre os corpos na cena - a própria mise-en-scène tem desequilíbrios e variações tortuosas. Não há um objetivo final, uma teleologia de sentido e de projeto. Glauber reelabora caminhos de Eisenstein, que esperava obter efeitos no espectador a partir do choque, indicar traçados ideológicos, propor posturas políticas pela montagem dialética e pela noção de atrações. "A montagem livre de ações (atrações) arbitrariamente escolhidas e independentes" (EISENSTEIN, 2008, p.191) era no cineasta russo a maneira de tentar levar o espectador a "perceber o aspecto ideológico daquilo que foi exposto, sua conclusão ideológica final" (2008, p.189). Com a montagem nuclear, Glauber já não forma conceitos por princípios de oposição e justaposição de partes. Há, muito mais, efeitos de suspensão e disjunção. Não há conclusão ideológica, mas o fragmento, a simultaneidade e a explosão atômica.

A Idade da Terra estaria próximo de "um painel ou mural, de uma colagem, na qual a organização espacial importa mais que o desenvolvimento no tempo" (BENTES, 1997, p. 66). Como obra que capta forças, trata-se de tornar visíveis e sensíveis elementos invisíveis, se pudermos trazer algumas formulações de Deleuze (2007) ao tratar da pintura de Francis Bacon. "É preciso que uma força se exerça sobre um corpo, ou seja, 
sobre um ponto de onda, para que haja sensação" (2007, p.62). O que Bacon opera na pintura é justo a composição de traços assignificantes, riscos numa tela, numa superfície, intensidades que já não representam. O pintor trabalha a Figura, para abrir a tensão com a figuração e mesmo com a abstração, que foi por algum tempo uma saída do pictural frente à narrativa. Ao pintar as forças, Bacon desorganiza o corpo.

A ldade da Terra opera uma captação de forças na própria mudança repentina de ritmos, na mistura de procedimentos, no descompasso e na surpresa. Nunca se sabe o que está para vir, não só se tratamos daquilo que está na cena, mas também de como a encenação se constituirá, de como os cortes irão acontecer, de como a câmera vai se movimentar. O efeito de desorientação faz sentir a imagem e o som em sua plasticidade e porosidade, em suas quedas e subidas, em sua produção no aqui e agora, como a trilha sonora feita ao vivo ou os giros que, num impulso, são feitos com a câmera. No desequilíbrio das sensibilidades é que o filme acontece. Justo na impossibilidade de um resultado ou de uma completude, $A$ Idade da Terra se lança ao mundo. São intensidades livres, nem metáforas nem alegorias, mas maneiras sensíveis de constituir formas de vida, de pensar possíveis para o estar no mundo, numa liberdade quanto às possibilidades de inscrição das imagens como seres físicos. Rio, Brasília, Bahia: espaços se inventam, conexões são possibilitadas pela imagem cinematográfica. Cristos se multiplicam: Cristo índio (Jece Valadão), Cristo militar (Tarcísio Meira), Cristo negro (Antonio Pitanga), Cristo guerrilheiro (Geraldo del Rey). A montagem extrapola a ideia de romper com a sequência de um início, um meio e um fim. Estamos, na verdade, sempre no meio, não há como começar ou terminar. Pode-se entrar por qualquer ponto, a obra se abre para ser seguida em direções várias. "É no meio que há o devir, o movimento, a velocidade, o turbilhão. O meio não é uma média, e sim, ao contrário, um excesso. É pelo meio que as coisas crescem" (DELEUZE, 2010, p.35). Ricardo Miranda, um dos três montadores - junto a Carlos Cox e Raul Soares -, discute essa montagem:

\begin{abstract}
A questão da montagem nuclear na verdade era um pouco isso: quando você não tem início nem fim, você não tem um plano inicial, você não tem um plano no final, não há um significado produzido pelos planos que começam e terminam o filme, como os filmes geralmente têm. O filme na verdade pode ser passado em qualquer ordem, o projecionista faz a montagem, ele que faz a estrutura final do filme.(MIRANDA, 2005)'.
\end{abstract}

Tomando mais de perto essa montagem, podemos perceber que Glauber recorre à repetição, ao acúmulo de planos, faz ouvir uma mesma frase várias vezes, faz ver a mesma cena se reinventar, reexistir ininterruptamente. Corta e interrompe, começa de novo ou já parte para outro ponto. Em uma sequência, o Cristo militar entra e sai

1 Participação de Ricardo Miranda em debate realizado em 27/07/2005, após a projeção de $A$ Idade da Terra na Sessão Cineclube no Cine Odeon. Disponível em: <http://www.contracampo.com.br/74/ idadedaterradebatecineclube.htm>. 
de quadro várias vezes. A mesma fala se repete e é interrompida pelo meio. A frase se dilui em pedaços. A curta cena compõe uma imagem diante de alguns pilares de pedra, em que dois personagens encenam uma relação dentro do quadro. Brahms e o Cristo Militar são os dois corpos nesse espaço. O plano é fixo, a câmera não se movimenta em nenhum momento para procurar um personagem, também não se aproxima de nenhum detalhe, não existe qualquer recurso de zoom. Trata-se de um retrato, composição de um quadro em que o entra e sai dá o tom. Tarcísio Meira ora entra pela direita, ora pela esquerda. Maurício do Valle está sempre em campo, com sua espada que tem um lenço verde na ponta. "Você já ouvir falar do negro Hassan?", grita o Cristo Militar. Corta para outro ponto do movimento do corpo pelo quadro, e a frase é tomada na sua segunda parte: "Comandante-geral das Forças Armadas de Ogulaganda!". Várias vezes, a montagem ressalta outro instante da fala: "Ele detesta a civilização!". O ator segue repetindo as frases, a cada vez com um tom mais alto, mais eufórico, o movimento mais acelerado. Ergue os braços, fala com veemência. Após a inserção de algumas cenas filmadas em outros lugares, o filme retorna a esse fragmento e o exibe em integridade, sem cortar nem a fala nem o movimento dos atores.

Nessas idas e vindas do Cristo Militar pelo quadro, falando as mesmas palavras, constantemente fendidas enquanto ditas, o filme faz do vai e volta um compasso musical. Ricardo Miranda, montador do filme dedicado especialmente às sequências filmadas no Rio de Janeiro, como essa aqui em questão, nos contou ${ }^{2}$ a respeito de uma provocação dada por Glauber no sentido de pensar o ritmo das imagens segundo a batida de um tamborim. Havia a orientação do realizador para que fossem aproveitados todos os takes das cenas filmadas: a saída na montagem foi emendar todos eles, interrompendo no caminho e construindo outro desenho do plano, a partir dessa colocação dos vários momentos em que se filma a mesma cena. Ao final, surge a cena no seu prolongamento, agora tomando apenas um dos vários takes, já sem o ir e vir. Na chave de leitura de Ricardo Miranda, seria aí o repique do batuque do tamborim, quando se fecha a batida, o gesto imagético que dá a marcação final do compasso. Depois das sucessivas quebras e da desmontagem em fragmentos, dá-se a ver o desenrolar sem intervir pelo meio, deixando o percurso de um corpo pelo espaço finalmente se completar. Tamborim segue o batuque.

A experiência de $A$ Idade da Terra é da ordem de um caleidoscópio. É um filme com o qual é possível brincar, montar e remontar visualmente, e nesse jogo, fazer o tempo se enlaçar. É a temporalidade do brinquedo, que pode ser pensada como constante restauração e reconstituição, um processo de redemoinho incessante que arrasta para a corrente do devir. São sempre desmontagem e montagem colocando-se em movimento,

2 Em conversa com o autor do artigo, realizada em agosto de 2013. 
é uma experiência do espectador, que trabalha remontando o filme na medida em que se insere no correr das imagens. O caleidoscópio produz tempos erráticos e constitui uma montagem de singularidades. Sempre experiências novas diante do visto, repetição diferenciante para o ver. O caleidoscópio oferece uma figura para pensar uma desmontagem crítica das coisas e para colocar a matéria como dispersão (DIDI-HUBERMAN, 2000, p.134). É um modelo óptico para pensar os tempos, na dupla relação entre visual e temporal. "Nas configurações visuais sempre 'irregulares' do caleidoscópio, se encontra uma vez mais o duplo regime da imagem, a polirritmia dos tempos" (DIDI-HUBERMAN, 2000, p. 134).

Glauber faz com que o tempo tenha várias faces, ele o insere na modalidade de um quebra-cabeça. Na produção incessante de fragmentos que não têm o encaixe dado, mas são remodeláveis, esse quebra-cabeça singular aponta para formas sempre por vir, para a potencialidade de uma constante formação de temporalidades, no perpétuo reajuste das peças. Uma brincadeira de desmontar um relógio para conhecê-lo melhor. Se o todo não se dá como sobredeterminação que a tudo abarca, o filme pode ser colocado numa mesa de trabalho, para ser operado, reposto, disposto, posto no correr do devir. O inacabamento não diz respeito a uma incompletude, como se ainda faltasse algo. É que, inacabado o filme, passam a ser repletas de virtualidades as relações que ele pode estabelecer com cada corpo. É uma obra que pode, ela mesma, ser colocada em relação com outras, são imagens que não têm uma amálgama que possa imobilizar a processualidade do filme. Uma experiência que não cessa de ser recolocada no turbilhão, aberta a mais desarranjos.

A Idade da Terra instaura outras condições de fruição na sua gestualidade. Ele demanda outras espacialidades. O diálogo desse trabalho de Glauber com a arte das instalações pode ser encontrado nesse exercício de transformar a obra numa abertura de entradas para o espectador, numa interpenetração de dentro e fora, no caráter inacabado que tem sempre pontas soltas, por serem associadas e dissociadas a cada novo olhar, por cada um que vê. E a singularidade do filme está no convocar o corpo a partir do olhar mesmo. Olhar é experiência de corpo. Essas obras nos acontecem, não enquanto sujeitos pessoais e identitários, mas como ondas que nos lembram, materialmente, sobre a fundamental necessidade de ter um corpo, comungado com outros corpos, na intensidade do acontecimento, em camas, greves, festas, revoluções.

Glauber faz assim o germe de seu Kynorama, o cinema integral, das múltiplas telas, de vários tempos interpolados, do raio laser e do holograma. Dizer que $A$ Idade da Terra se transforma, já na sua escritura, em uma filme instalativo implica que o corpo faz por ele um percurso, como quando se percorrem as salas de uma galeria, fazendo escolhas e, ao mesmo tempo, tendo algumas orientações pela montagem imaginada pelo exercício da curadoria. De uma sequência a outra, o filme faz uma curva, toma uma nova direção, tem outras cores, outro movimento de cena, toda uma nova percepção é demandada ao olhar, para se habituar às novas formas que se abrem. O espectador segue trabalhando. Esses trânsitos pela espacialidade inventada no filme, enquanto movimentos por blocos, 
são saltos descontínuos por experiências e por lugares. E no caso dessa obra em especial, os lugares são tanto fílmicos quanto geográficos mesmo, é a conexão atordoante e sem fio de sentido entre Salvador, Rio e Brasília.

Se ainda existe algum país como horizonte aqui, como era comum nos filmes de Glauber dos anos 1960, é um país completamente estilhaçado do ponto de vista espacial, formado senão por fragmentos incapazes de formar um todo. É um filme que tem vários filmes virtuais em sua escritura, como se outras escrituras pudessem ser compostas a cada experiência de encontro com a obra. Não existe uma necessária relação entre um momento e o outro e, se por razões extrafílmicas, a estrutura randômica durante a projeção não pôde ser efetivada, é preciso dizer que ela está na obra, como que armazenada em potência. A obra se faz, se produz, nela mesma, como movimento randômico, e cada bloco não tem uma agregação necessária com o outro, do que resulta a possibilidade de associar e dissociar de infinitas maneiras, para que vários filmes sejam criados a partir do filme, vários desvios sejam traçados no percurso da relação, diferentes e singulares caminhos sejam inventados pelo trabalho do espectador.

Érico Oliveira de Araújo Lima é doutorando no Programa de Pós-Graduação em Comunicação da UFF e pesquisador no LEEA-UFC.

ericooal@gmail.com.

\section{Referências}

BENTES, I. O devorador de mitos. In: BENTES, I. (org.). Cartas ao mundo: Glauber Rocha. São Paulo: Companhia das Letras, 1997.

DELEUZE, G. Francis Bacon: lógica da sensação. Rio de Janeiro: Jorge Zahar Ed., 2007. . Um manifesto de menos. In: DELEUZE, G. Sobre o teatro. Rio de Janeiro: Jorge Zahar Ed., 2010.

DELEUZE, G.; GUATTARI, F. Kafka: para uma literatura menor. Lisboa, Assírio e Alvim, 2003.

Mil platôs: capitalismo e esquizofrenia, vol. 1. São Paulo: Ed. 34, 1995

DIDI-HUBERMAN, G. Devant le temps: histoire de l'art et anachronisme des images. Paris: Les Éditions de Minuit, 2000.

FLUSSER, V. Forma e material. In: FLUSSER, V. O mundo codificado: por uma filosofia do design e da comunicação. Rafael Cardoso (org). Tradução: Raquel Abi-Sâmara. São Paulo: Cosac Naify, 2007.

O universo das imagens técnicas: elogio da superficialidade. São Paulo, SP: Annablume, 2008.

EISENSTEIN, S. Montagem de atrações. In: XAVIER, I. A experiência do cinema: antologia. 4. ed. Rio de Janeiro, RJ: Graal, EMBRAFILME, 2008. 
GUMBRECHT, H. U. Produção de presença: o que o sentido não consegue transmitir. Rio de Janeiro: Contraponto: Ed. PUC-Rio, 2010.

ROCHA, G. Revolução do cinema novo. São Paulo: Cosac Naify, 2004. 